\title{
Cosmopolitan Sophistry: Grounding Politics in Disorder and Uncertainty
}

\author{
Jonathan Marshall \\ University of Technology, Sydney
}

\begin{abstract}
Conceptions of the State, Nation and politics, in play in 'the West', usually descend from totalitarian models which are primarily Platonic in origin. They aim for unity, harmony, wholeness, legitimate authority and the rejection of conflict, however much they claim to represent multiplicity. By expressing a vision of order, such models drive an idea of planning by prophecy as opposed to divination, as if the future was certain within limits and the trajectory was smooth. Chaos theory and evolutionary ecology shows us that this conception of both society and the future is inaccurate. I will argue that it is useful to look at the pre-Platonic philosophers, in particular the so-called sophists Gorgias and Protagoras and Heraclitus with their sense of ongoing flux, the truth of the moment, and the necessary power of rhetoric in the leading forth of temporary functional consensus within the flux. This ongoing oscillation of conflict provides social movement and life rather than social death.
\end{abstract}

\section{Opening}

This paper begins by asserting the importance of disorder and proceeds to caricature some aspects of primarily English speaking 'Western'1 cosmopolitan/multicultural theory while pointing to some of the creative paradoxes and tensions which arise within cosmopolitanism’s use. Amongst many paradoxes I point to cosmopolitan exclusion, suggesting that as cosmopolitanism involves a rhetoric of group category creation and an attempt to make unity, it may create and enforce an outside category and therefore undermine itself. I then argue that these cosmopolitan caricatures carry implicit theories also found in Platonism, and suggest that some pre-Platonic, or sophistic, philosophers (in particular Heraclitus, Gorgias and Protagoras) give insights useful to social theorists and cosmopolitans generally, as they emphasise the failure of definitions as a mode of knowing, the flux and indeterminacy of reality, the relevance of paradox, the necessity of conflict and the importance of creative rhetoric in establishing social groups. I then further outline a rhetorical process of group formation and show how this impacts on our understanding of the paradoxes

\footnotetext{
1 'Western' is not a fixed absolutely definable category, any more than are 'developed', 'first world', 'global north' or other handy terms of the day. It shifts around ambiguously. The main point of using the term is to draw attention to the possibility that there are 'non-western' cosmopolitanisms, which escape the arguments presented here, although I think this unlikely. 'Western' is not so much meant as a marker of inclusion, as a marker of limits.
} 
and incoherencies of cosmopolitan politics and analysis. Finally, the paper concludes with some pointers towards further thought.

As 'cosmopolitanism' serves an explicit rhetorical function it is sophistic from the beginning. It further claims to be both a term of analysis and a political objective to which we are to be persuaded, and it deals with multiplicity, apparent contradictions and unity. Within the sophist framework these features are not necessarily disorders but conditions of possibility. How we use terms politically or sociologically becomes part of the sociological or political dimension of life. These are not separate domains, and the term works through its evocation of opposites and the dynamics of disorder. Disorder cannot be ignored in the manner in which implicit Platonist seekers of ideal fixed truth and method do.

\section{Disorder}

Readers will not find an axiomatic, orderly and logical argument here, but that is the point: the argument assumes that the world is also messy and largely unpredictable ${ }^{2}$. Let us begin by proposing some axioms:

- Disorder is always present, and often produced by modes of ordering. The more we strive for an order the more our modes of ordering may disrupt that order, or produce apparent paradoxes.

- Disorder varies from moment to moment: it is not an eternal 'object'.

- Disorder is political. It is defined or perceived differently from different social positions and different aims. So is order. What looks like order from one point of view can look like mess from another. In that way, order is also messy (Marshall 2010).

Despite disorder being intertwined with order, we social theorists and cosmopolitans (and definitions of who 'we' are, are always messy ${ }^{3}$ ) prefer to separate them. Disorder and disordering processes, tend to be either ignored by models and analyses (disorder is, for example, deleted from ideal types almost by definition), or disorder is seen as temporary or as a pathology - an indication of decay or transition.

\footnotetext{
${ }^{2}$ An overly orderly presentation arguing that disorder is important may appear to be a contradiction, and thus undermine the points being made. Yet if the argument is disorderly, then people may never arrive at the points, or become exasperated in the journey. Hopefully, should it arise, that exasperation will still convey something to the reader about our collective attitudes towards disorder.

${ }^{3}$ A cosmopolitan paradox could centre around the question of whether, and when, the term 'we' is inclusive and 'cosmopolitan', or exclusive of its unmentioned other. I am using 'we' to indicate I am not external to, or above, the discourse I am currently discussing.
} 
If we describe a dynamic mess as if it was clear, ordered, static and predictable then we not only distort it, but use it as a Rorschach blot, seeing what we hope and fear, and perhaps try to clean it up, or harmonise it according to those views, destroying it in the process. We may try to order the world to alleviate our own anxieties rather than act with attention to the world itself.

Disorder is often implicated in definitions of evil as loss of wholeness or as viscous and slimy (Russell 2011). To the contrary, virtue is often defined in practice as clearing up disorder or as making order and harmony - but if disorder is natural and ordering can make disorder, then such virtue risks creating further problems. Possibly people are at their worst and most severe, when they think they are doing good and removing the disorder that troubles them. Considering this problem may cause us to ponder both applying our virtue, and the ill effects of not acting. It renders life more realistically complex.

\section{Caricature}

Whenever we summarise, or map, we distort. The summaries presented here are caricatures; they are exaggerated and don't pretend to completeness as do ideal types, or normal descriptions ${ }^{4}$. Good caricatures are disturbing and disorderly. They are not likely to be taken as real. They have meaning in a particular moment (which shall later be discussed as kairos) and give attention to the potential of that moment. We may also be moved to wonder as to why we see a caricature as being like what it models; what are the limits of distortion before it becomes unrecognisable? What is involved in the (rhetorical) creation of similarity and difference, or the placing of 'things' in differing or similar categories?

\section{Cosmopolitanism: a caricature of its ideals}

Cosmopolitanism is hard to define. "Cosmopolitanism is, of course, a contested term; there is no uniform interpretation of it in the growing literature” (Beck \& Sznaider 2010, p. 382). There are distinctions made between 'institutional' and 'moral' cosmopolitan, everyday cosmopolitanism and presumably non-everyday cosmopolitanism, and so on (see the papers

\footnotetext{
${ }^{4}$ Distortions are not always and inevitably caricatures of course, however, we cannot limit what people will do with distortions, anymore than we can limit what they can read into a body of messages. When something becomes a sign it escapes its maker's (or other's) intentions. Therefore attempts at communication can lead to either disharmony ('how could they think I meant that?'), or to repressive exercises of power in an apparently necessary attempt to stabilise meanings. Distortions, even if meant to be accurate, can become caricatures depending on how they are used - the question here is whether this is intentional, and self aware, or not.
} 
in Brown \& Held 2010). We may be tempted to say that everything is terminally unclear and incoherent.

Nevertheless, as caricature, I suggest that the categories 'Cosmopolitanism’ or 'Multiculturalism' seem to express a family of ideas which include: ${ }^{5}$

- Living together with difference in relative harmony.

- Mutual respect.

- That dialogue, or presence, can lead to understanding.

- Ideals like universal Democracy or universal Justice are vital.

- A hope for stability or continuing order.

- Legitimate authority and the rejection of conflict.

- Increasing global interaction and shared risk.

- A hope for world government of some kind

- A degree of mobility of some parts of the population. (See papers in Brown \& Held 2010; Appiah 2006; Archiburgi 2008; Beck 2006; Carey 2003).

There often seems to be a sense that because we need cosmopolitanism, it will necessarily happen.

[T] he cosmopolitan outlook means that, in a world of global crisis and dangers produced by produced by civilization, the old differentiations between internal and external, national and international, us and them, lose their validity and a new cosmopolitan realism becomes essential to survival (Beck 2006, p. 14).

This is perhaps an example of a theorised order and harmony being used to relieve anxiety about disorder.

While cosmopolitanism is not a fixed thing, it does imply a universalism and an ordering or an aimed for harmony. Use of the term may also attempt (successfully or unsuccessfully) to undermine the importance of some previous splintering identity categories such as race, religion, kinship or national culture, in favour of a wider order. Appiah (2006) for example thinks that we can establish commonalities amidst dialogue and getting used to each other while Zizek (1999) suggests that we need a universality for political action. From a perspective which sees disorder as important, we may also wonder what disorders cosmopolitanism creates, and what we undermine, or ignore, through its application.

\footnotetext{
${ }^{5}$ Not all these ideas must be present of course, but at least some of them will be. For more on the social use, construction and contestation of categories see Marshall (2006).
} 
Some of the family of ideas underlying cosmopolitanism, as described above, have paradoxical overtones. Democracy can lead to leaders attempting to gain support for themselves by stirring the hostility of a majority (or large minority) towards others. Justice is decided through relations of power, conflict, condemnation and exclusion, and through the argumentative creation of similarity or difference to precedent and social category. Bringing people into contact or dialogue can emphasise differences that they were not previously aware of, and were formerly quite happy to ignore; even using the same language may not always lead to mutual understanding. Cultural borrowing can be a form of exploitation. Connection can spread disruption speedily through networks. Political integration can lead to new disputes, spreading of old disputes, and pushing of responsibility elsewhere (as when people won't act on climate change unless everyone else does). Localisms may be strengthened in opposition to globalisms, while being spread through globalisation. Movement of peoples can lead to the building of physical, and other, barriers. Similarly, can we always ask everyone (slaves and slave owners for example) to exist in harmony? Cosmopolitanism is enframed in tensions between: nation and diaspora, local and global, cultural and universal, power and suppression, purity and borrowing, hybridity and ethnic cleansing, relativism and global ethics, preservation of difference and levelling of difference. These oppositions collide, rather than separate out in accord with a desire for analytic neatness.

There are also some common criticisms of 'cosmopolitanism' which display some further paradoxes in the idea, such as:

- Cosmopolitan tolerance involves power and marginalises those being tolerated (Brown 2008).

- Cosmopolitanism is a western concept tied in with western imperialism or capitalist globalisation, and requires that we ignore histories of imperialism (Cheah 2006) ${ }^{6}$. Harvey (2000, pp. 532ff.) points out that Kant's cosmopolitanism, often considered the foundation of contemporary cosmopolitanism, is connected to something resembling a white supremacist geography.

- To be truly cosmopolitan and live together in harmony we should all become Christians, Muslims, capitalists, communists, Indians, or perhaps cosmopolitans. This hardly needs comment, other than to point out yet again

\footnotetext{
${ }^{6}$ As with Appiah's claims that, say, aboriginal ownership of relics is the same as Disney’s ownership of Mickey Mouse and an infringement of universal cultural rights (2006, p.130).
} 
the difficulty of defining 'cosmopolitanism' universally. Appiah calls such monotonic cosmopolitanisms 'counter cosmopolitanisms' (2006, chapter 9) and Fine (2007, pp.142-3) points to forms of Nationalism, wherein the interests of a particular nation state become taken as universal.

- Multicultural versions of cosmopolitanism essentialise identity, reducing it to ethnicity thus producing “caged ethnicities” (Hage 1998) and risk increasing interethnic violence (Sen 2006).

- Cosmopolitanism is a revolt of the mobile elites against the localised masses (Delanty 2006, p.26).

- Cosmopolitanism, as sociological analysis, depends on the decline of the nation state and the even-globalisation of the economy everywhere, but there is little evidence this is happening; we cannot even agree on common action on climate change (Lind 2011). Cosmopolitanism is a hope or policy not a current reality.

\section{Cosmopolitan Tensions and Prophecy}

The pro-cosmopolitan school seems to load the term 'cosmopolitanism' with theories emphasising the unifying consequences of conversation, globalisation, political integration, NGO presence, cultural borrowing, justice and so forth, without much reflection on the disunifying processes. The basic implication seems to be that we could all live in harmony if only we just increased our virtue or changed our thoughts, and thus that achieving cosmopolitanism is largely a matter of correct policy and good will. However, the evidence from the world is not that encouraging. Even if you achieved correct policy it may not remain correct as relationships change. Similarly goodwill cannot always be maintained. The anticosmopolitan school focuses on the fracture without seeing any unities, which is equally unreal. Indeed, the criticisms of cosmopolitanism come from a cosmopolitanism point of view, seeing it as not harmonious enough. In other words, the idea of cosmopolitanism, while useful and perhaps essential, is inherently paradoxical and prone to self-undermining.

These contradictions go to the heart of cosmopolitan politics, leading either to relativism in which we accept anything provided it is 'within cultural tradition' or to the assumption that some morality is obvious and universal. Thus Beck and Sznaider write:

The principle that women and children should not be sold or enslaved, the principle that people should be able speak freely about God or their government without being tortured or their lives being threatened - these are so self-evident that no violation of them could meet with cosmopolitan tolerance (2010, p. 399). 
This cuts out a great deal of the world that we might want to interact with. Appiah's book is filled with similar glosses, but nevertheless some principles remain "If you are the person in the best position to prevent something really awful, and if it won't cost you much to do so, do it” (2006, p. 161). Not perhaps an over onerous demand, and easy to avoid as there is almost always an imagined other person who could take the action.

A fundamental paradox in the good intentions in cosmopolitan politics arises when it meets those who would destroy it from within. That is, issues of cosmopolitan tolerance or acceptance of an enemy, who may not even be an intentional enemy. What does a cosmopolitan do with people who cultivate ignorance of others, who denounce other forms of understanding, or who work to prevent such understanding? This is a marked problem in an information society, where limitation of information to bias confirmation is relatively easy. If cosmopolitans do not take seriously the option that there are those who wish to destroy cosmopolitanism, then those cosmopolitans are not open to the culture of the other, and are not embracing a cosmopolitanism that takes others seriously. If, however, we do take these others seriously and decide to exclude them because they are hostile to our culture, then we violate our principles and lose persuasiveness and moral justification. More shall be said on this later.

Cosmopolitanism is a theory with consequences which acts as a guide for action as well as analysis. A position of intentional harmony through ordering (whether excluding or not), implies that human life is conscious, that we know all the variables and the ways they interact, and can predict the result of our actions ${ }^{7}$. As a result, cosmopolitan theory implies that we can plan by a model of prophecy. That is, we can declare the future (and the results of our actions) with certainty, as opposed to divination a continual looking at the signs at that moment (kairos) - as if the future was determined within limits and the trajectory to that point was smooth. However, chaos theory and evolutionary ecology shows us that this conception of both society and the future is inaccurate as, in sufficiently complex interactive systems, increasing accuracy in our observations does not converge on a particular result, as is the normal statistical assumption, but may give widely variant results (the so called

\footnotetext{
${ }^{7}$ Once admitted, unconscious processes point to the non-simplicity of our self which constantly faces disruption by the necessary ordering processes of the ego, and which disrupts that ego in turn. Without some idea of the dynamics of unconscious processes (and our resulting attractions to that which we suppress, or our tendency to project our own 'evil' onto disorder, or onto those who thwart us), then we will never understand why plans are disrupted.
} 
butterfly effect). Similarly while these results depend upon 'initial conditions', in social life there are no simple initial conditions. Something has always preceded; hence the selection of initial conditions is largely arbitrary (Prigogine 1997).

Prophecy also becomes attractive because we think we understand people, when in fact not only do we fail to understand others, even others close to us, but we do not understand ourselves - and possibly cannot understand ourselves and others (Watts 2011). Test how well you can predict any person's behaviour exactly over a two day period. The chances are high that you will not do very well. You certainly won’t predict much of what they will be thinking, or how they (or others) might interpret what is said or done. People are not a class or fixed category (understanding one business person is not understanding them all), and understanding to even a limited degree takes work and openness to correction.

\section{Plato}

The idea being proposed is that cosmopolitanism is not definable, is self undermining or paradoxical, is open to argument and, at best, will posses some of a number of characteristics, making for endless debate as to whether a particular system is cosmopolitan or not.

Politically, cosmopolitanism implies an ability to predict the consequences of people's actions and of policies which seems implausible. Ideas that cosmopolitanism can be defined independently of the rhetorical/political processes that create a version of it, or that it will necessarily arise from current social processes, either ignore or prematurely resolve these issues.

To try and explain why cosmopolitanism seems to be conceived as a relatively simple unity, let us return to Plato and caricature. I assert that most politics today is Platonic and monotheistic because it seeks to impose order, it sees order as natural and virtuous, and ONE. Within this schema, disorder is the result of ignorance, vice or sabotage, not just of the way things work; disorder is rarely seen as inherent or potentially informative. The political and philosophical aim is unity, harmony, wholeness, legitimate authority and the rejection of conflict. I will try and contrast this Platonism with a 'sophistic' approach - hopefully without making that approach too uniform ${ }^{8}$.

\footnotetext{
${ }^{8}$ The issues are not purely 'western', a similar kind of contrast might be made between Taoism and Confucianism; again with ambiguity as its easy to do a Taoist reading of Confucius and because Taoism, as practiced, has tended to become Confucian. Perhaps the same point could be made with Charvaka against almost every other Indian philosophy, or between some Sufisms and mainstream Islam.
} 
It is, in this argument, of little concern that Plato is sometimes totalitarian, as probably few people are directly influenced by the Republic or the Laws, and that subject is already covered by Popper (1949) among others. Plato is perhaps a bit more ambiguous than this in reality (Clark 2003). No one can be rigorously Platonic; the ideal always has to be violated to maintain the ideal. Anyway, if Plato is not always an explicit Platonist, we can still look for the signs of Platonism, which are:

- Belief in definition - categories are permanent, and all things with the same name must be similar in the same way. Things exist, corresponding to the terms, with explicit commonality, or the person is engaging in meaningless ignorance. In this view, democracy and cosmopolitanism are not political terms argued over by particular people and groups and used to evoke a particular hope, but terms which either refer to a reality (or potential reality), or are without meaning.

The standard process of a Platonic dialogue is that Socrates asks for a definition. If the person interrogated cannot give one, or prefers to list by example, they are declared to be ignorant. Socrates' move against sophists has two pincers. First to try and get the sophist to delimit what they are teaching. Thus a shoemaker would make shoes, what does a sophist make? (Plato Gorgias §447). If the sophist, in Plato’s writings, agrees to this form of interrogation (which they might not in reality), then Socrates asks them to define what it is they are teaching/making. If the sophist cannot define this so as to cover all cases, then they have shown themselves to be ignorant and incapable. Plato would suggest that we should either get a correct definition of cosmopolitanism, or abandon it altogether To the contrary, sophism suggests, that not only 'cosmopolitanism', but many other terms which are important in delimiting social and political groups, inherently cannot be defined, and that it is necessary for them to be ongoingly understood through rhetoric and action for them to 'work' at all. In a Platonic view, all the elements of cosmopolitanism, as discussed above, must be necessary or present when the term cosmopolitanism is used, if they are relevant for that term. Again a sophistic view denies this and would accept a list of potential and shifting factors. 
- Belief that the ideal world is static or harmonious. Hence we can ignore the mess of this world. When combined with the first expectation that all real things can be defined, this can lead people to expect their categories to be both static and abstract. Goodness, for example, is enduring and orderly. We are not interested in this good, but The Good, as good is eternal and universal. There is no flux in reality, only in appearance or in the secondary world. In this view, clear ideas are more important than mess, and indeed they exclude it, so the actual disorderly world becomes secondary to the ideal world of ideas. This kind of attitude appears unconsciously when people assume that the Ruling Class is a whole or has one set of interests, that Nations exist, that Justice has a force in itself and can be agreed upon, that pure cosmopolitanism (without paradox) can exist or manifest in harmony, or that Good cannot destroy anything that is not evil and thus that if cosmopolitanism is good it has no harmful consequences.

As should be clear from the famous story of the cave in The Republic ( $\$ 514 \mathrm{ff}$ ), the philosopher brings back the vision of order from the real abstract world to the disorderly prison of this world. Platonists look first for theorised harmony and integration, and give them causal priority or importance. At the end of The Cratylus (§440), where Socrates dialogues with a follower of Heraclitus, Socrates suggests that if all is flux, then naming cannot work and we cannot know anything. This might be unfortunate, but it does not mean the world has to depend on static abstractions, or that mess is not an important part of reality.

- Everything has one opposite. Therefore, if the opposite of democracy is tyranny, there must be nothing in common between any specific examples of democracy or tyranny. Static, abstract categories can be kept pure in ways which non ideal categories and realities cannot. For example in the Platonic dialogue Protagoras, Socrates argues that "everything has one opposite and not more than one" so as to declare that Justice is one unified thing with no touch of the impure disorder of intemperance (§332ff). In this view differences tend to become melded into oppositions and opposites cannot be present together, or be dynamically interesting. Thus a Platonist wishing to use the term cosmopolitanism must repress its multiple opposites and incoherencies; sophists would celebrate and utilise them. 
- There is only one type of truth. Approximation or mess is a denial of truth. This is expressed in the Cratylus as mentioned above, and the Protagoras continues the ideal of tidying by removing oppositions as stated above. Hence mess cannot be really real and thus may need to be suppressed, which (in theory) will not diminish anything.

- Dialogue can lead to rapprochement, virtue or justice, and uncover or transmit knowledge. Plato implies that real dialogues work better than written ones, but nevertheless the overwhelming idea is that dialogue (dialectic) leads in a positive direction. As I have already suggested dialogue (however cosmopolitan) can increase disagreement, conflict and the appearance of injustice. What is good in one situation may not always produce what you think is good in another.

- If we know what is good and what it is to be good then we will seek this good. This is essentially Socrates' theory of virtue, and why theory is so important to his virtue. If we do not attain the good through knowledge, and not everyone can, then we must be compelled to seek it by the knowledgeable elite of philosopher kings. The metaphor Plato deploys is that of the physician. If the patient refuses to do what is necessary for their recovery then they should be compelled (Gorgias §477ff, §480, §521). We might contrast this with Gorgias, who according to Plato, argued that the person who knew persuasion was perhaps more effective in helping a patient than a good physician who could not persuade (ibid. §456). Gorgias’ position implies both a degree of democracy and free will amongst the ruled, and a degree of practical 'makedo' in the situation rather than the imposition of perfection across all situations. Plato's position implies that correct knowledge is found in advance through discussion and then acted upon, while the sophist implies that knowledge is found while doing.

- True philosophers are reluctant to be political. The Republic, argues that the best people, the philosophers, will not rule voluntarily. Plato's famous allegory is the 'Ship of State' in which a ship's crew mutiny against the captain, thinking all are equal. The crew will never choose the wise, and apparently dreamy, philosopher to tell them what to do, and disaster results. "The philosopher should not beg of mankind to be put 
in authority over them” (§488ff). This is functionally convenient as Platonists then don't have to risk an encounter with real politics and mess; they can stay in their ideal world of pure ideas and virtues.

\section{Sophists}

Let us carry these criticisms of Plato further by looking at pre-Platonic philosophy in more detail. Heraclitus, Gorgias and Protagoras are what I will call sophists of flux. They have differences as well commonalities, but here I am primarily interested in their differences from Plato. This is another caricature.

At the conclusion of his dialogue The Sophist (§268) Plato characterises a sophist as a person who causes self-contradiction, imitates appearance, and juggles words. Sophists were also criticised by Plato for having no roots, for wandering and attracting foreigners, which suggests some cosmopolitan default (Tell 2011, Chapter 5). However, it seems likely that sophist cosmopolitanism was more a denial of ties to one place or culture, than it was an assertion about universality; there is no forced unity here. Aristides also claimed that Plato reviled the sophists because of his "contempt both for the masses and his contemporaries" (Sprague 1972, p. 1), which could imply that sophists were at least interested in those 'masses'.

It needs to be emphasised that compared to the shelves of Platonic writings that have survived from the Ancient World (from Plato, through Albinus, Philo, Plotinus, Proclus, Porphry, Iamblichus, to Simplicius and the neo-platonic commentators on Aristotle), the Christian Platonists (Clement of Alexandria, Origen, Augustine) and the Islamic Platonists (Al-Kindi, Al-Farabi, ibn Sina), almost nothing survives of the writers we are about to discuss - just a few sentences here and there, and some paragraphs largely by enemies. They have almost been removed from history.

People still wish sophists to be removed. Alain Badiou, who is known as an activist philosopher, claims it is the job of philosophy to destroy sophism and flux yet again something he does first by attacking the early Wittgenstein; and then abusing the late Wittgenstein as sophist, thinking we shall take that as argument enough. The purge must be performed to gain philosophic purity. For Badiou sophism is philosophy reflected badly and 
emptied of truth (Bosteels 2011, pp.25ff). I suggest sophism is politics emptied of monotypical truth, and good intentions emptied of one truth only.

Sophists should be annoying, and turn everything over: they should be superficial, in order not to pretend to the profundity or depth which comes from avoidance of disorder and paradox. Let us begin with Heraclitus, although he is not usually considered to be a sophist, as he sets down some of the basics.

\section{Heraclitus}

Heraclitus is often known as 'the obscure', and the fact that he survives in fragments helps render him more obscure. One saying is:

The way up and down is one and the same (§60; Sweet 1995, p. 27).

The path goes both ways, however much we want it to go one way only. If we insist that it only goes one way then we are suppressing 'things', or generating a paradox. The point is, that by analogy, 'oppositions' can exist together, not disconnectedly, and this is what gives a thing/event its usefulness. Cosmopolitanism can be productively paradoxical and bidirectional, as that is the nature of terms and reality.

Carl Jung quotes the following fragment which is not found in the usual collections of Heraclitea (1953, p. 425, n.37).

Fate is the logical product of enantiodromia creator of all things (Stobaeus Ecl. i. 60).

Assuming this fragment is genuine, Heraclitus is arguing that we switch from one thing to another, in particular from one opposition to another, or that events proceed from interplay. There is never just 'the one', or even the one direction. Increasing the strength of one pole at the expense of another, leads to oscillations which, if held back, produce collapse. A strong cosmopolitanism, may generate a strong reaction against it. More generally Heraclitus argues that:

What is in opposition is in agreement and the most beautiful harmony comes out of things in conflict. All happens [or, 'is born’] according to strife (§8; Sweet 1995, p.5).

Disorder and conflict, action and reaction, are part of dynamics. They are not always bad, and may be essential. 
For the harmony of the universe, like that of a lyre or a bow, is by alternatives, and in mortal affairs there is nothing pure and unmixed. But as in music there are low notes and high notes, and in grammar there are vowels and consonants, yet a musician or a grammarian is not the man who dislikes and avoids the one or the other, but rather the man who knows how to use all and to blend them properly so also in human affairs, which contain the principles of opposition to each other; since, as Euripides has it,

The good and bad cannot be kept apart,

But there's some blending, so that all is well

(Plutarch de Tranquill. §15; p.219)

Cosmopolitanism can be driven by conflict. Its harmonies arise out of allowed, expected and cultivated dispute, or out of clashes with forms of anti-cosmopolitanism. In any case, its manifestation depends on art, as much as, if not more than a set of rules, fixed definitions or prophecies.

Heraclitus argues for the importance of change. Seneca writes:

And I, while I say these things are changed, am myself changed. This is what Heraclitus means when he says, into the same river we descend twice and do not descend, for the name of the river remains the same, but the water has flowed on. This in the case of the river is more evident than in case of man, but none the less does the swift course carry us on (Patrick 1969, §41).

For Platonists, there is a fixed place in the soul or in God, for Heraclitus there is no fixed place, nor is there any place outside, from which to forge fixedness. Life does not stay the same and attempts to fix life, or forms of life, produce death. The ever-presence of flux, undermines normal concepts of 'being' - there is no stasis or purity, never a moment in which 'something' is not changing into something else. Similarly, cosmopolitanism is not fixed and neither are the people who participate within it; everything is in flux forever.

One consequence of this situation is that the categories we use to explain the world are themselves deceiving because they attempt to stop flow. The world escapes language, but we have to use language to understand and act on the world. Even more disconcertingly, flux may or may not be orderly: “The fairest kosmos is random pile of sweepings” (§124, Sweet 1995, p. 51). If the world is not orderly, then it is not predictable in detail and we must always adapt to the kairos, the moment, and flux, not to an imagined abstract perfection or fixed aim. It implies we need to abandon our sense that we can prophesise, rather than divine, 
what will result from our and other's actions. Uncertainty is fundamental and words/ categories distort flux.

\section{Gorgias \& Protagoras: Rhetoric as Philosophy and the Moment of Virtue}

Gorgias and Protagoras take paradox, opposition, the uncertainty of flux, and the distortion of words seriously. For Gorgias, it appears that there are some central terms. The meanings are necessarily hazy, so the explanations here are not firm; they are plausible. Others may say differently.

- Rhetoric: Gorgias and Protagoras are both associated with rhetoric. Rhetoric, according to Aristotle (1926), is what we use when we argue from uncertainty. Contrary to Aristotle, sophism recognises that uncertainty is the normal state, not an inferior one. Therefore, we humans are forced to make use of comparison, probability, and plausibility and always use rhetoric.

- Paradoxologia involves moving out of the commonplace, and being aware of the arguments on 'both' sides; the potential similarities and differences between 'things'. We could tie paradoxalogia to the opposites of Heraclitus and the statements of Protagoras that there are two possible positions on every question, opposed to each other (Sprague 1972, p. 13; Plato Protagoras §331). The recognition of fundamental uncertainty makes it worthwhile to be aware of all the possible arguments which can be discovered, and not be devoted to the One argument. That way we can respond to the moment rather than the ideal. Lawyers and judges may need this awareness to find as much truth as possible amidst their uncertainty in a trial.

- Kairos is the name given to the properties of moment and implies attention needs to be given to that moment. As there is no ideal, there is, for example, no generalised and definable areté (excellence, virtue). There is 'only' the areté of this moment and the persons involved; the point of power depends on the kairos, so the techniques (say of cosmopolitanism) used at one moment, may not work later. There is always flux. Smith argues that kairos

points to a qualitative character of time, to the special position an event or action occupies in a series, to a season when something appropriately happens that cannot happen just at 'any time,' but only at that time, to a 
time that marks an opportunity which may not recur (2002, p. 47).

- Political knowledge is universally distributed. Plato reports Protagoras as arguing that political wisdom was distributed amongst all humans by the Gods, otherwise we could not live in society (Protagoras §322ff.). Thus, at best, the philosopher is one of many, an adviser and teacher, but not an ideal ruler. The sophist has some faith in the wisdom of others. A good cosmopolitanism, if it can arise in all its splinteredness and dynamics, will arise from the bottom up, even if seeded, and exemplified, by the sophist. That is the sophist's limit. If people resist, then that resistance may express some unperceived political wisdom, not just evil or ignorance, and this could be attended to.

- Understanding by listing and multiplicity: As we have argued, Plato assumes that important terms can be defined, that all eventualities of what we label by a term are the same, and that if we find the right meaning we have solved the problem. So much as we can reconstruct Gorgias position, he refuses this. As already stated, the best one can do is not to define areté (virtue or excellence) but to list examples of it relative to kairos, social position, aims, work being done etc, and to exemplify it yourself. Areté is not understood uniformly. Thus, we can list ideas which could be part of 'cosmopolitanism', without caring whether the term can be properly defined, or whether everyone agrees on the absolute vital factors of its definition.

Protagoras and Gorgias and other sophists open the questions of 'what if we don't know what is beneficial or virtuous, or if the virtuous is not beneficial for someone, or what if we don't agree on virtue, or what is virtuous at one time is not at another? What if there is no ideal justice, no ideal virtue, no single benefice? What if the law benefits the law enforcers? What if, as Heraclitus implies, every kairos is different? If you cannot step into the same river twice, or even once?'

A thing might be good for some persons but bad for others, or at one time good and at another time bad for the same person, [but they are not the same] (Dissoi Logoi in Sprague 1972, pp.279ff.).

This approach leads to the common accusation by those who believe in rules, definitions and the oneness of virtue, that sophists are not virtuous. However, without the need to define everything for all time and space, we can admit that some 
may, at some times and less at others, not be well disposed to certain aspects of cosmopolitanism; they may even find themselves harmed by it. This reinforces the necessity of listening to the discontents who tell us about disorders we do not perceive. We can then worry whether this harm is internal or paradoxical to the project, despite our intentions, rather than retire into a certainty of good. This oscillation is part of reality.

- Power of Words. Gorgias insists we are never removed from words, and words have consequences. Words alter the psyche as if by witchcraft. We cannot see the whole truth of all the past or the present (as memories are not the past), and so words are what make the situation real to us, or present it to us, and in doing so bind the soul (Sprague 1972, p. 52). Gorgias also points out that words are not the things themselves and thus do not re-present things or events (ibid., p.46). We are always dealing with approximations, swayings and inclinations. We can be using the same words but understanding them differently. Whether we like it or not we live amidst magic. "[T]he process of cosmopolitanization is bound up with symbol and ritual, and not just with spoken ideas” (Beck \& Sznaider 2010, p. 388). Again cosmopolitanism can be seen as a rhetorical art, or magical act, which brings itself forth, amongst many different rhetors with no single focus, in a specific kairos.

- Truth. Plato holds geometry is truth, while Aristotle tells us that Protagoras argues that geometrical objects, like perfect circles and tangents do not exist (Sprague 1972, p. 22). For sophists, models are not real. The actual properties of things in this world, their disorders, are more important than models. The kairos of events is different, so the events are different, although we must make them similar to be able to talk about them, and thus we could explore the kinds of processes involved in creating similarity and difference for us. Just as sophists deny the existence of 'The Good' but don't deny that acts/events can be more or less good in a particular kairos, so they deny the existence of 'The Truth' but don’t deny that statements can be more or less true in that kairos. Recognising that truth is problematic and even momentary, we might avoid taking our implicit understandings and models as eternal and necessarily the case. 
I will briefly assert there are different types of true statement, although the following list is not meant to be exhaustive.

- Definitional: where things are defined as being the case. A cat is a mammal of the genus felis. $1+1=2$. Consistency of definition is important, and may lead to uncovering other properties of the world as so defined.

- Propositional: Where things are said to be the case, and within the boundaries of the definitions and other means of checking seem to be the case. The cat sat on a lap.

- Close enough for practical purposes. The cat is half a metre long; all measurements are imprecise.

- Symbolic or poetic: Statements about ultimate, or basic, things will tend to be symbolic as they are currently beyond human knowledge or ability to know literally. The symbols will rhetorically and symbolically point towards these ultimates. Similarly poetic metaphors can lead to understanding, insight or relationship, but it would be a mistake to take these metaphors as literal. A lover is not a summer's day. Atoms did not turn out to be hard or indivisible.

- Procedural: knowing how to do something. Take the cat for a walk as opposed to saying 'she is taking the cat for a walk'. Note the person may not be able to tell you how to take a cat for a walk so that you can do it, but could perhaps point you in the direction.

Only with definitional truth can there be absolute accuracy. In the other cases there is the possibility of better accuracy or accomplishment; nothing is ever done perfectly, so truth is not exhausted or fully expressed, but it can get 'better'. What counts as 'true enough' may vary with different social aims, and different rhetorics of framing and grouping. It is not that there is no truth, but acting in reality outside of pure definition, some degree of error (and appropriateness to the moment) is as good as it gets. We can act and continually test our predictions and the accuracy of our statements, or play with the definitions. Is Snaffy a cat or a tiger? Is Pauline a Catholic or an Australian? (or is that a meaningful question?) Is multi-culturalism cosmopolitan? Part of the art of rhetoric is to point out the probabilities and to create our perceptions when things are unclear - which is most of the time. Rather than saying there is no truth, as is often alleged, the sophist's question is 'what are the 
criteria of truth in a particular situation?' While truth is not one, some statements can be true and some can be true enough.

- Finally, Sophists, as opposed to Platonists, do not seem to have assumed that you can learn from dialogue. Gorgias for example in his list of situations of persuasion, implies that in dialogue you may be persuaded to things or make mistakes which you might not, if you were to stand back and think carefully (Sprague 1972, p. 81). Contrary to Plato, there are circumstances in which we might prefer a book to dialogue, because the book cannot interrupt our thinking process and cannot so easily send us down false trails; we can reflect upon it. Sophists, in their teaching procedure, seem to have assumed that people learnt, not by dialogue or just by accumulation of knowledge, but by emulation, and by encountering problems in their lives and working out how to deal with them with hands-on help. To use a Platonic simile: is it possible to teach a person to make shoes by talking about it alone? Or to make cosmopolitanism by debate alone? The sophist position is that you learn by being in the presence of one who knows or does (as best they can), and follow them and are corrected by them. Then you might go to another sophist etc. You learn by apprenticeship, not by reading or talking. Learning is social, not abstract. If you wish to teach, you teach by example, which you cannot avoid doing anyway. If, in dealing with the cosmopolitan paradox, you suppress those who oppose your cosmopolitanism, then you are teaching that cosmopolitanism is about suppression. Fighting terror with terror risks legitimating the original terror.

Sophism suggests a connection between truth, uncertainty and social-rhetorical processes. In particular it gives the sense that a) words and reality are always changing; b) that the creation and recognition of truths involves the creative use of language; c) that this can create potential oppositions and messes, and; d) that this is important in social, political and moral life. By pushing identity into category and rhetoric, sophism politicises it; identity is what you do politics with, with others and against others. It is creative. This is made clearer by more recent work on group formation and persuasion by Nick Hopkins and Steve Reicher (1997), and this allows us to think further about the creation of cosmopolitan identities and their relations to others. 


\section{Categorisation Theory}

Hopkins and Reicher add to sophist ideas about the importance of rhetoric in positioning us in uncertainty and creation. They argue that rhetoric is social and that rhetorical language has the potential to use and construct social-group categories and affiliations so as to include us with others, exclude us from others, and position us against others. It matches agreement with conflict. In a paper on an abortion debate Hopkins \& Reicher (1997) show how effective persuaders:

- Define category boundaries so as to include as many of the audience as possible;

- Try to make the audience and speaker part of a common category;

- Construct the recommended actions or beliefs as congruent with this category and, if possible, as a good example of category behaviour; and finally

- Try to make opposing arguments represent an outgroup category.

We are more easily persuaded by someone who we categorise as belonging to our own selfcategory, and less easily persuaded by those we categorise as belonging to an outgroup category. Making some belief or behaviour a good example, or prototype of how, a member of social category should behave “depends upon increasing differences from outgroup members and decreasing differences from members of the same category” (Turner et al 1987, p.155). Because of this dynamic of persuasion, groups, by moving away from their perceived prototypes of negatively valued others, can move to an 'extreme' position rather than towards an existing more 'median' position, which might be closer to the other group (ibid., p. 151). The prototypic response of a group does not necessarily correspond to the ingroup mean of responses (ibid., p.80-1). Conflict framing can strengthen categories, thus causing 'ambiguous' individuals to be expelled and help bring group members to the extreme position. For example, while the average Republican in the US may share much with the average Democrat, the rhetoric of persuasion, separation and purity has tended to drive Republican prototypes further towards 'the right', dragging with them those who identify as part of that group. This effect has been unintentionally promoted by Democrats moving to the right and attempting to take over the 'middle' ground. Making a group different from our own, which of course they are as no groups are the same, tends to suppress recognition of what the groups have in common, while rendering all members of that group similar. 
In other words, to persuade people of things risks destroying the possibilities of what you aim for. Again we are faced with another paradox. Dedicated cosmopolitan persuasion, and creation of a cosmopolitan self-category, risks creating an 'other' (a non-cosmopolitan selfcategory) and forcing people into it, so as to distinguish them from good cosmopolitans. These excluded people may also embrace and create the category to distinguish themselves from cosmopolitans.

If faced with the original cosmopolitan paradox we opt for the exclusion of those who don't tolerate or are hostile to cosmopolitanism, we may need to wonder whether the categorygroup we are excluding and creating is uniform or whether we are making them uniform. Indeed, by creating uniformity and opposition, we may be making people who were prepared to co-exist, classify themselves with the excluded and their hostile ideology, and thus generating support for our overthrow.

Problems of increasing category opposition are particularly marked when, in order to remove oppression and increase inclusion, you have to emphasise the oppressed category and the differences between the categories involved, even if you want to emphasise their similarities. Without this emphasis on difference, on not fitting in, on opposition, you cannot talk about the oppression. This talk also leads to increased conflict, possibly increased unhappiness, and risks destroying the recognition of similarities and bondings, and hence inclusion. Yet it may be necessary.

Politically, we can say that particular categories may or may not be useful for motivating groups at particular times - again the kairos is important. Thus the category of 'working class' may no longer work politically in Australia, partly because the Right has associated the category with failure, and disharmony. It is hard to say who is working class, or can identify as working class - accountants, minor managers, artists, police etc? - yet it is still a major way of framing different interests and stopping them from being subsumed into the interests of a more dominant group. Similarly, views which accept the unified 'other', intensify images of their power, thus talk of the Ruling Class, can make this object seem real and unified and thus unshakeable, when this may not be the case. The unification is both real and unreal. We cannot talk about it without giving it properties it may not have, and making it appear more insurmountable than it is. 
Talking about groups politically and coming to understand them can firm those groups in their oppositions, magnify the oppositions, and increase frictions. Attempts to remove oppression or promote unity can be paradoxical.

\section{Counter-Plato}

Instead of world which is (or should be) ordered, by abstract models, harmony, unity, definition, constancy and absence of contradiction, we might consider a world in which:

- Flux is basic.

- Variation is important (similarity and difference are not always given).

- Categories vary with use, and this is part of their use.

- Definitions are useful but do not always produce knowledge. Words and categories change in meaning and application depending on the kairos, the comparison, and the context or framing of the word-event. How we frame the questions will affect our answers.

- Not everything belonging to a category belongs in the same way. We can define by listing.

- Increased communication can promote disharmony. Learning does not just occur through dialogue, and dialogue is often not enough.

- Persuasion can increase oppositions, as can attempts to recognise oppression.

- Conflict and harmony (opposites) exist together. Paradox is basic. States of affairs can both reinforce and undermine themselves.

- There is no single overall virtue or justice. Virtue is not just knowledge.

- Rather than 'the general' we consider the moment (the kairos), 'things as they are' at this time.

- Feedback and iterative unpredictability of complex systems is taken for granted -hence the concern with kairos.

- Philosophers do get involved in politics and thus discover things; this is how they learn and the purpose of philosophy is practice. The sophist is not focused on another ideal world.

- Political sense (or confusion) is not confined to philosophers or the particularly knowledgeable.

- We recognise disorder as always present, political, and intertwined with ordering systems. Disorder is not necessarily bad and can be informative.

\section{Comments: the Cosmopolitan Hope?}

The mess now hopefully forms some kind of knot, having chaotically circulated around various issues in the disorder of cosmopolitanism, tying them together but not completely. The main problem I have presented is that order, even cosmopolitan order, tends to undermine itself. Discussion and persuasion can also undermine their own aims and create conflict, isolation and otherness. Certainly there is nothing in communication or being together that automatically produces harmony. The kairos can lead in either direction, and 
indeed, harmony may not be required. Even if we had order, we would still have disorder. Simply put, the world is not as implied by Plato. I have further tried to show that pre-Platonic sophism directs our attention to these problems, and is thus more useful to cosmopolitans, than an implicit Platonism.

What then is the way forward?

Firstly we accept that cosmopolitanism, as process and as term, is non-definable and not static. There is no Platonic ideal conception; it shifts with the moment. As some already recognise, this is not necessarily bad:

Cosmopolitanism may... be a project whose conceptual content and pragmatic character are not only as yet unspecified but also must always escape positive and definite specification, precisely because specifying cosmopolitanism positively and definitely is an uncosmopolitan thing to do (Pollock, et al. 2002, p.1).

So let us not be too Platonic in our worries about definition. We can list good and bad characteristics to be realistic, and explore how these interact and interfere with each other. The term 'cosmopolitanism' may refer to many types of attempted truth; procedural, poetic and propositional. It is a term of group formation and exclusion. It is both rhetorical and analytic together (it includes oppositions) and this may be confusing; it is not always useful to criticise one direction from another. It is perhaps more important to exemplify it than to discuss it; abstract knowledge is not enough, but knowledge is useful.

Rather than being fixed in categories (without compulsion) people generally belong to, or identify with different groups, depending on context and moment, which also unsettles their identity and allegiances. Sometimes they can be in categories which seem contradictory from the perception of other categories. The one does not exclude its other. These identities and allegiances will further shift with their perception of kairos, the histories of group relationships to one another, and the persuasions being attempted. Thus again, with persuasion we have to be aware of the context, moment, and the ways the groups have been constructed previously. 
Rather than just look for integration or conflict we look for both (or more) ${ }^{9}$.

If something enables, how does it restrict?

If it connects, how does it separate?

If it orders, how does it disorder?

If it stabilises, how does it destabilise?

If it produces harmony, how does it produce disharmony.

If it establishes communication how does it sever communication? And so on.

Sophism assumes that social life is unpredictable, and this is a phenomenon of life for everyone; order is always slipping away, or our plans are being annihilated. If members of 'the ruling class' conspire to promote their order, this may undo them. There is no uniform direction to history, and increased interconnection opens both stability and instability. Bearing this in mind:

We look at how social attempts at order fail, and how those failings, and rescuings, are part of society.

We look at the things/flows which don't fit - what do those things/flows do?

We ask what is the garbage that is essential for social production or without which production could not occur, and what does it do?

We don't assume that 'things/events', whether categories or objects, or people, stay the same; they are all in flux - we ourselves change as we talk and move.

We recognise that every moment can be a potential tipping point, but we cannot be sure if it is, or which way our actions will tip events, until after the moment has passed. We divine rather than prophesise.

We recognise that the emergent is not simply and linearly determined, but determined by a network of causation, balancing and disruption. We look for unintended consequences.

Yet we recognise that we also resist change, we are not able to flux in every way.

If we use ideal types let us construct ones that are confessedly caricatured, that have their rhetoric spelt out, not hidden.

Social categories are not fixed, but argued over.

People belong to overlapping categories which can conflict.

People do not all belong to a category in the same way.

We don't assume communication, or interaction, works towards harmony.

Culture is driven by difference, misunderstanding, misinterpretation, reinterpretations, ordering and disordering.

\footnotetext{
${ }^{9}$ With more space I'd discuss the importance of moving from oppositions to multiples, or at least threes, as these undermine the sense of opposition alone.
} 
There are multiple framings of, and different understandings of, events. The events themselves come into flux, or existence, out of this conflict of understanding and action.

Second guessing is also a social fact. We act because we guess how someone will act in response, and they likewise... There is again no simple interpretation or causality. And these guessings are interpretations, and possibly mistaken.

“Things” dissolve into flux - like storms.....

The term cosmopolitanism is supposed to indicate cosmopolitanism is happening and help movement towards its achievement, but its use may have other consequences. Therefore we remain uncertain and attentive. Life is complex and social analysis should reflect this.

\section{Conclusion}

Implicit Platonism suppresses disorder, paradox, irregularity and uncertainty; explicit sophism recognises their importance. A focus on disorder, does not imply an assumption that humans are intrinsically conflictual, or threatened by their 'animal nature' (whatever that is) or that they need cultural or religious discipline. If it appears that way, then that is the order which arises by making a contradiction and then allying with one side of the contradiction alone. Even if humans were totally and absolutely co-operative, which they aren't, then their attempts at ordering would still necessarily fail sometimes, and need constant correction. Life is always chaotic - perhaps especially when we try and order things.

Trying to work without disorder is a bit like trying to do engineering or physics without friction or entropy; this is something which people did attempt until relatively recently. It is hard to keep disorder in mind, and hard not revert to harmony, to purely constructive thinking, or to prediction rather than divinatory attention to kairos. To get anywhere we have to look at the forces of integration, dispersion or disintegration, and productive and destructive conflict. Indeed, it is hard to think of disintegration as good, but sometimes things need to be taken down to be rebuilt.

In social life, there can be no more than a passing harmony of difference, but this ongoing oscillation of conflict provides social movement and life rather than social death, and I would suggest that any working cosmopolitanism will operate in this movement between integration and disintegration, order and disorder, paradox and truth. 


\section{References}

Appiah, K.E. 2006, Cosmopolitanism: Ethics in a World of Strangers, Allen Lane, London. Archibugi, D. 2008, The Global Commonwealth of Citizens: Toward Cosmopolitan Democracy, Princeton UP.

Aristotle 1926, The 'Art' of Rhetoric, trans J.H. Freese, Loeb Classics, Cambridge, Mass. Beck, U. 2006, Cosmopolitan Vision, Polity, Oxford.

Beck, U. \& Sznaider, N. 2010. 'Unpacking cosmopolitanism for the social sciences: a research agenda', British Journal of Sociology, vol. 61(Supplement 1), pp. 381-403.

Bosteels, B. 2011, 'Translators introduction', to Alain Badiou Wittgenstein's Antiphilosophy, Verso, London.

Brown, G.W. \& Held, D. 2010, The Cosmopolitanism Reader, Polity, Oxford.

Brown, W. 2008, Regulating Aversion: Tolerance in the Age of Identity and Empire, Princeton UP.

Carey, D. 2003), 'The Cosmopolitan epoch: Configuring a just world order', Culture Mandala: The Bulletin of the Centre for East-West Cultural and Economic Studies, vol. 6, no.1, pp. 1-25.

Cheah, P. 2006, Inhuman Conditions: On Cosmopolitanism and Human Rights, Harvard UP.

Clark, R.B. 2003, The Law Most Beautiful and Best: Medical Argument and Magical Rhetoric in Plato's Laws, Lexington Books, Lanham.

Delanty, G. 2006, 'The cosmopolitan imagination: critical cosmopolitanism and social theory', British Journal of Sociology, vol.57, no.1, pp. 25-47.

Fine, R. 2007, Cosmopolitanism, Routledge, London.

Hage, G. 1998, White Nation: Fantasies of White Supremacy in a Multicultural Society, Pluto Press, Annandale.

Harvey, D. 2000, 'Cosmopolitanism and the banality of geographical evils', Public Culture, vol.12, no.2, pp. 529-564.

Hopkins, N. \& Reicher, S. 1997, 'Social movement rhetoric and the social psychology of collective action: a case study of anti-abortion mobilization', Human Relations, vol. 50, no.3, pp. 261-286.

Jung, C.G. 1953, Collected Works of Carl Jung Vol.6: Psychological Types, Princeton UP.

Lind, M. 2011, ‘Against cosmopolitanism', Breakthrough Journal, no.1, pp. 25-34. http://breakthroughjournal.org/content/BTJ_issue1.pdf

Marshall, J.P. 2006, 'Categories, gender and online community', E-Learning, vol.3, no.2 http://www.wwwords.co.uk/elea/content/pdfs/3/issue3_2.asp\#10 2010, 'Social disorder as a social good', Cosmopolitan Civil Societies Journal,vol. 2, no.1, pp. 21-46. http://epress.lib.uts.edu.au/ojs/index.php/mcs/article/view/1337/1608

Patrick, G.W.T. 1969, Heraclitus of Ephesus: a New Edition Combining in One Volume the Fragments of the Work of Heraclitus of Ephesus on Nature and Heracliti Ephesii Reliquiae, Argonaut, Chicago.

Plato 1952, The Dialogues of Plato trans B. Jowett, Encyclopaedia Britannica, Chicago.

Plutarch 1939, Moralia, Vol VI, Loeb Classics, Cambridge, Mass.

Pollock, S.I., Bhabha, H.K., Breckenridge, C.A., \& Chakrabarty, D. 2000, 'Cosmopolitanisms', Public Culture, vol.12, no.3, pp. 577-589.

Popper, K. 1949, The Open Society and its Enemies: The Spell of Plato, Routledge, London. Prigogine, I. 1997, End of Certainty, Free Press, New York.

Russell, D. 2011, 'The experience of evil: Its archetypal \& sensual dimensions' http://www.jungdownunder.com/links_main/Speakers_Presentations/2011/August/The \%20experience\%20of\%20evil\%20August\%202011.pdf 
Sen A. 2006, Identity and Violence: Illusion of Destiny, Allen Lane, London.

Smith, J.E. 2002, 'Time and qualitative time', in Sipiora, P. \& Baumlin, J.S. (eds.) Rhetoric and Kairos: Essays in History, Theory, and Praxis, SUNY UP, New York, pp.46-57.

Sprague, R.K. 1972, The Older Sophists, University of California Press.

Sweet, D. 2007, Heraclitus, Translation and Analysis, University Press of America, Lanham.

Tell, H. 2011, Plato’s Counterfeit Sophists, Center for Hellenic Studies, Harvard University, Cambridge Mass.

Turner, J. C., Hogg, M. A., Oakes, P. J., Reicher, S. D. \& Wetherell, M. S. 1987, Rediscovering the Social Group: A self-categorization theory, Blackwell, Oxford.

Watts, D.J. 2011, Everything Is Obvious: *Once You Know the Answer, Crown Business, New York.

Zisek, S. 1999, The Ticklish Subject: The Absent Centre of Political Ontology, Verso, London. 